\section{CAMPAIGN LAUNCHES IN MANCHESTER TO RAISE AWARENESS OF THE 'SILENT DISEASE'}

The British Society of

Periodontology (BSP) has launched a UK campaign to raise awareness of gum disease aimed at both dental professionals and the general public.

The campaign, part of a Europewide initiative led by the European Federation of Periodontology (EFP), will target dental professionals over the next two years to show they are checking on everyone's gum health and making improvements where necessary.

Professor Iain Chapple, head of Periodontology at the University of Birmingham (UK) and EFP Treasurer, said: 'As a clinician, you assume that people know what periodontitis is. But though they might be familiar with the term 'gum disease' the vast majority don't know what periodontitis is, how common it is or that it is a silent disease until it's too late. I think if the public did know those basic facts a lot of people would be a lot more motivated towards getting it checked out.'

Eight out of ten adults over-35 suffer from some kind of gum complaint and recent research suggests that there are links between healthy gums and general

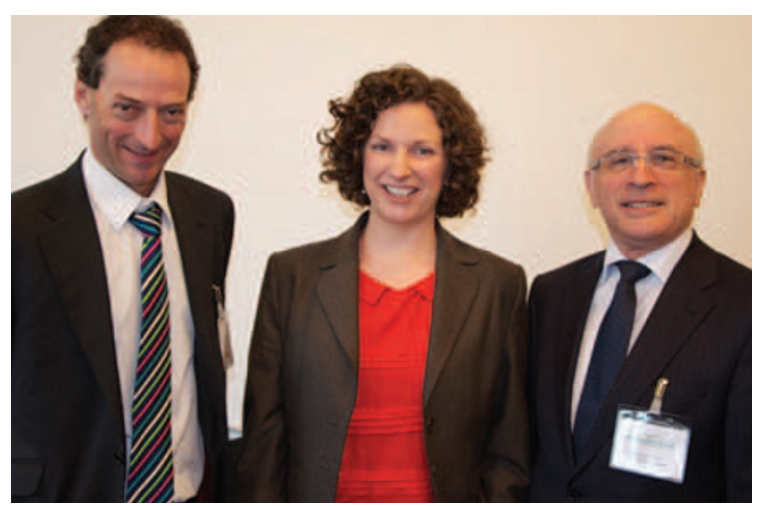

(I-r) lain Chapple, head of Periodontology at the University of Birmingham, Ruth Doherty, BDJ Managing Editor and Philip Greene, president of the BSP at the recent BSP Spring Meeting in Manchester

well-being, including systemic illnesses such as diabetes and cardio health. The research, gathered over a period of 30 years, also raises the possibility of periodontal health check-ups becoming future screening points for the diagnosis of other systemic illnesses. This means dentists will work more closely with specialists such as cardiologists in spotting the warning signs of cardiovascular complaints.

Such evidence was the focus of a systematic scientific review procedure in Spain last November where leading European and US dental academics gathered to discuss a key selection of reports. Further information and a video describing the review workshop can be found at www.efp.org/.

The BSP will be embarking on many activities across the country over the coming months to educate and engage the public and health professionals about the importance of periodontal care.

\section{HAS CAROLINE REGISTERED WITH YOU?}

Caroline Winifred Norma Graham, born 13 June 1969, was last known to be alive around Easter 1989. There are no confirmed sightings of her since that date and it is believed that she has been murdered.

The Retrospective Major Investigation Team of
Carrickfergus, Co. Antrim, are appealing to all dental professionals to check their records to confirm if anyone by the name of Caroline Graham has registered with them.

To respond, call 02890700727.

\section{EL DENTISTA JAILED FOR MOBILE DENTAL PRACTICE}

A US dentist known as $E l$ Dentista to his clients has been jailed for practising without a licence, distribution of a controlled substance, attempt to commit a felony, conspiracy and a warrant in a traffic case, according to the $A B Q$ Journal, a publication based in Albuquerque, New Mexico.

Eliver Kestler, aged 36, of Santa Fe, made home calls to clients in a red 2001 Chevrolet, with police photographs showing a fishing tackle-style box containing drill bits, syringes, false teeth and vials of drugs.

An undercover police officer contacted Mr Kestler saying that he had toothache and was visited by the red Chevrolet within the hour, with Mr Kestler wearing blue hospital scrubs. It is reported that Mr Kestler had a business card reading 'Dentista' and informed the police officer that he had a licence to practise dentistry in Mexico and was seeing patients in Santa Fe to 'make ends meet'.

Police found drugs including epinephrine, septocaine, diprospan and a syringe with an unidentified clear liquid inside in El Dentista's car. Police were unable to determine whether he had a licence to practise in Mexico. 